\title{
BMJ Open Relationship between workers' return to work, job retention and income in industrial accidents in Korea: a longitudinal study
}

\author{
Suk Won Bae (D) , ${ }^{1,2}$ Inchul Jeong (1) , ${ }^{3}$ Jin-Ha Yoon (1) , ${ }^{1,2,4}$ Seung Wook Lee, ${ }^{5}$ \\ Tae Hyun Kim, ${ }^{6,7}$ Jong-Uk Won ${ }^{1,2,4}$
}

To cite: Bae SW, Jeong I, Yoon J-H, et al. Relationship between workers' return to work, job retention and income in industrial accidents in Korea: a longitudinal study. BMJ Open 2021;11:e039948. doi:10.1136/ bmjopen-2020-039948

- Prepublication history and additional material for this paper are available online. To view these files, please visit the journal online (http://dx.doi. org/10.1136/bmjopen-2020039948).

Received 30 April 2020 Revised 16 February 2021 Accepted 22 February 2021
Check for updates

(C) Author(s) (or their employer(s)) 2021. Re-use permitted under CC BY-NC. No commercial re-use. See rights and permissions. Published by BMJ.

For numbered affiliations see end of article.

Correspondence to

Dr Jong-Uk Won;

juwon@yuhs.ac

\section{ABSTRACT}

Objective This study aims to compare workers' income before and after an occupational injury, with regard to return to work and job retention, over a period of 5 years. Design This study was designed as a longitudinal study. Setting The Panel Study of Workers' Compensation Insurance (PSWCI) survey targeted workers involved in industrial accidents for which medical care was terminated in the year 2012.

Participants The panel study was conducted on a final sample of 2000 workers who were selected proportionally by region (nine regions) after priority assignment by disability rating (six levels). A total of 1458 workers were finally included in this study.

Methods This study used data from the first to fifth PSWCI. To identify the effect on income after occupational injury considering return to work and job retention, we used the generalised estimating equation.

Results In regard to workers' return to work, the $\mathrm{OR}$ that income after an occupational injury would be higher than that before an occupational injury was $3.17(2.41-4.17)$ for those who returned to original work and 2.32 (1.81$2.97)$ for those re-employed as compared with who did not return to work and 1.27 (1.07-1.15) for those who retained their job as compared with those who did not. The ORs were 2.91 (2.26-3.75) for those who were reemployed and retained jobs and $2.96(2.15-4.08)$ for those who returned to original work and did not retain jobs as compared with those who did not return to work and did not retain jobs.

Conclusions It is important for accident victims to retain their jobs to maintain their economic status.

\section{INTRODUCTION}

According to the Korean Ministry of Employment and Labor, 102305 workers were involved in industrial accidents in 2018, which translates to an accident rate of $0.54 \% .^{1-3}$ Compared with the previous year, this number has increased by $13.9 \%$, while the accident rate has increased by $0.06 \% .^{3}$ The trend of workers involved in industrial accidents over the past 10 years shows that the number of workers involved in industrial
Strengths and limitations of this study

- This study is the first to examine the changes in income based on return-to-work status and job retention for Korean workers involved in industrial accidents.

- The data used in the study are from the only panel study in Korea conducted by the Korea Workers' Compensation and Welfare Service with a 5-year follow-up on the quality of life of workers who had been involved in industrial accidents.

- One limitation to this study is that we did not consider the effect that a disability compensation lump sum would have on income after occupational injury.

- Because the year of the accident was not recorded, income before occupational injury was calculated using the duration of medical care.

accidents has steadily declined since 2009 , but increased sharply in 2018 and still exceeds by about $90000 .^{1-5}$

Industrial accidents have significant negative impacts from multiple perspectives. ${ }^{246}$ Specifically, workers involved in industrial accidents are burdened by worries of recovery and anxiety about the future. ${ }^{78}$ Loss in labour force due to industrial accidents can cause economic problems due to the loss in human resources in charge of household income or the loss of social labour force beyond an individual-level problem. ${ }^{9} 10$

The amount paid out for workers' compensation for industrial accidents in Korea was approximately KRW 4 trillion (US\$3.3 billion) in 2017 , which was a $3.64 \%$ increase from the previous year. The estimated economic loss (direct and indirect loss) in the same year was approximately KRW 22 trillion (US\$ 18.0 billion), indicating an increase of $3.64 \%$ compared with the previous year. ${ }^{12}$ Industrial accidents cause significant loss, both 
directly and indirectly, to the country, business owners and workers alike. ${ }^{2}$

Workers' compensation insurance was adopted in many countries to protect workers who experienced an occupational injury. ${ }^{11} 12$ One of the main goals of workers' compensation insurance was to ensure that workers who have been involved in industrial accidents return to work. ${ }^{12}$ In Korea, the concepts of social return and return to work were promoted by the Korea Workers' Compensation and Welfare Service (KCOMWEL) by establishing a customised rehabilitation support service via medical care. This led to the return-to-work rate increasing from $50.1 \%$ in 2011 to $65.3 \%$ in 2018 for workers involved in industrial accidents. ${ }^{13}$

For workers involved in industrial accidents, return to work can induce social balance after occupational injury by reducing the negative impacts and reducing the economic burdens of both workers and the government. ${ }^{4514-17}$ Previous studies have been conducted to examine the return-to-work rate of workers involved in industrial accidents. Factors that affect the return-to-work rate were personal factors (eg, gender, age, marital status, education level, household income and subjective health status), occupational factors (eg, industry employed in before the industrial accident, occupation, number of employees, duration of employment and status of worker), degree of disability after the accident, length of hospitalisation, length of medical care, hospital quality and primary physicians' and employers' interest in return to work. 59 18-30

Although it is essential to identify workers' return-towork rate and job retention status to ensure successful return to work, research on workers' status after their return to work is insufficient. ${ }^{5}$ While a few studies have examined workers' compensation for industrial accidents or changes in their income according to their disability rating, industries before the industrial accident and economic activity after the occupational injury, ${ }^{2} 412$ 31-33 studies that directly examine changes in income following return to work and job retention after occupational injury are severely lacking. Furthermore, few studies have directly calculated the amount of income that is lost when workers with injuries are unable to return to work or return to a workplace that is different from their original one, in the long term. We hypothesised that while there may be an initial increase in income from various compensation measures that are awarded by insurance companies and the government to individuals who have had an occupational injury, after a certain period (maximum of 5 years), all injured individuals suffer from a decrease in income.

Thus, the objectives of the study were to examine workers' income before and after an occupational injury according to return to work and job retention and to investigate exact yearly changes in income.

\section{MATERIALS AND METHODS}

\section{Study design and participants}

This study used data from the first to fifth Panel Study of Workers' Compensation Insurance (PSWCI), which was conducted to establish, manage and advance workers' compensation insurance policies. The PSWCI collected dynamic time-series data by surveying workers involved in industrial accidents. The PSWCI survey targeted 82493 workers involved in occupational injuries for which medical care was terminated in the year 2012; the panel study was conducted on a final sample of 2000 workers who were selected proportionally by region (nine regions) after priority assignment by disability rating (six levels). Panel surveys have been conducted annually, the first in 2013 and the fifth in 2017. Interviewers conducted face-to-face interviews and employed a computer-assisted personal interviewing method to obtain responses from participants. $^{2452634-36}$

By the fifth panel study, 1616 of the original 2000 respondents completed the survey showing a retention rate of $80.8 \%$. Longitudinal non-response bias emerging from survey drop-outs was controlled for by using sample weights to adjust for each wave. These sample weights were provided by the PSWCI to be used by researchers incorporating longitudinal data analysis. The ratio of unequal selection probabilities due to missing observations was calculated and further adjusted for poststratification, trimming and raking ratios, to compensate for changes over time among certain classes and characteristics (ie, income data which increase naturally over time). The PSWCI also incorporated Kalton and Kasprzyk's regression imputation method, to predict the values of missing responses for crucial variables.

Owing to the difficulty of estimating the explanatory variable if the duration of medical care after occupational injury exceeded 2 years, such respondents were excluded from our model. Moreover, we excluded workers who were either self-employed or employers at the occupational site at the time of injury. Lastly, we excluded 13 respondents who did not have a response for the explanatory variable.

\section{Patient and public involvement}

Patients and public were not involved in the research process.

\section{Sociodemographic characteristics}

Age in years was categorised into five groups: $<30,30-39$, $40-49,50-59$ and $\geq 60$. Marital status was categorised into three groups: not married, married and others (separated, divorced or widowed). Education was categorised into three groups: less than high school, high school and college or above.

\section{Occupational-related characteristics}

Industry was classified according to the Korean Standard Industrial Classification which is based on the International Standard Industrial Classification. The 
manufacturing and construction industries accounted for more than half of occupational injuries and illnesses (manufacturing accounted for $26.8 \%$ and construction accounted for $27.1 \%$ in 2018). ${ }^{3}$ Therefore, the occupational industry was categorised as either manufacturing, construction, service or others.

The following occupational characteristics were based on the job the worker had at the time of occupational injury. The worker's employment status was categorised as either a regular worker (permanent job) or a daily worker (temporary job and daily job). Self-employed individuals and employers were excluded. The number of employees was classified into four groups: $<5,5-9,10-29$ and $\geq 30$. The duration of employment was classified into three groups: $<1$ year, $1-3$ years and $\geq 3$ years.

\section{Injury-related characteristics}

The type of occupational injury was divided into two categories: injury or disease. If workers endured an occupational injury or illness and met the requirements for industrial accident compensation, then they received a disability rating. ${ }^{37}$ In accordance with the Korean Industrial Accident Compensation Insurance Act, the disability rating ranged from 1 to 14 with a lower rating indicating a more traumatic injury. ${ }^{24}$ This study categorised disability ratings into five groups: 1-3 (critical), 4-7 (severe), 8-10 (moderate), 11-14 (mild) and none.

\section{Return-to-work-related characteristics}

PSWCI included six types of economic activities. These included return to original work, re-employment, selfemployment, unpaid family work, unemployment and economic inactivity. Returned to original work refers to workers involved in occupational injuries who return to the occupational site of the industrial accident after completing medical care. Re-employed workers are workers who were re-employed (paid work) at a site other than that of the industrial accident at the time of the survey. Self-employed means those individuals who own business or freelancing. Unpaid family work refers to assisting a family or relative for more than 18 hours per week (3-4hours per day or more). Those who looked for a job more than once in the past 4 weeks for income and responded that they would work if they found a suitable job within the past week were categorised as unemployed. Economic inactivity means that the individuals have not looked for a job more than once in the past 4 weeks for income or responded that they could not work even if there was a suitable job within the past week. ${ }^{26}$ In this study, participants who returned to original work or were self-employed were categorised as return to original work, participants who were re-employed were categorised as re-employed and participants who were unpaid family workers, unemployed or economically inactive were categorised as non-return-to-work. Work retention was defined as maintaining employment for 24 months or longer at the same workplace. ${ }^{5}$

\section{Main outcome variables}

The main outcome variables of this study were income before and income after a worker's occupational injury. Income before occupational injury was determined by the following question: 'What is the average monthly wage at the workplace (ie, job) where the industrial accident occurred?'2 4 Income after occupational injury was estimated as the sum of the individual's earned income and non-work income. Earned income includes wages and business income, and non-work income includes disability lump sum income and disability pensions related to industrial accidents. We excluded property income and private transfer income, which were not related to industrial accidents. $^{24}$

\section{Statistical analyses}

The general characteristics and incomes of the subjects before an occupational injury considering return to work and job retention were analysed using a t-test and an analysis of variance (ANOVA). We used a repeated measures ANOVA, linear mixed-effects model and generalised estimating equation (GEE) to analyse longitudinal and repeated measures data. A 'lag' effect was given as a test of robustness, for panel data analysis.

The respondents' annual income before and after occupational injury considering return to work and job retention-their income before occupational in jury and their 5-year average income after occupational injurywere compared using a repeated measures ANOVA. To identify changes in income after occupational injury considering general characteristics, we used a linear mixed-effects model for analysis by setting the value of the income after occupational injury minus the income before occupational injury as the dependent variable. To identify the association between post occupational injury income and return-to-work status and job retention status, we used a GEE to calculate ORs with 95\% CIs. All analyses were performed using SAS statistical package V.9.4 (SAS Institute).

\section{RESULTS}

Table 1 displays the income before occupational injury for each participant characteristic, stratified by return-towork status. The participants mean annual income before occupational injury was KRW 29.26 million (US\$24000) for the return to original work group, KRW 25.98 million (US\$ 20000) for the re-employed group and KRW 22.26 million (US\$18000) for the non-return-to-work group. The proportion of men was relatively high in all three return-to-work groups. The income before occupational injury was higher in men compared with women in all three return-to-work groups $(\mathrm{p}<0.0001$ for all three groups).

The general characteristics of the "non-RTW (Retuento-work) group', 'returned to original work' group and 're-employed' group were different, according to age, sex, industry, severity of injury and other variables. As 


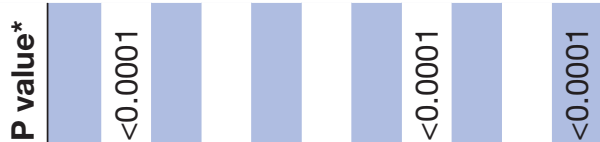

$\stackrel{\hat{\sigma}}{\circ}$

$\overline{8}$
○े
v

$\overline{8}$
○ุ
v

$\infty$
$\infty$
10
0
0

厄.

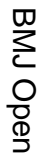

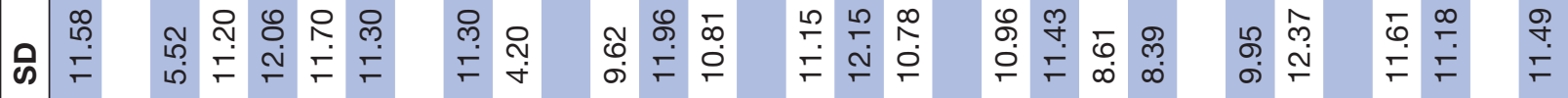

ॠ

๑ొ

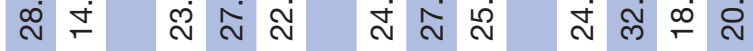

ले

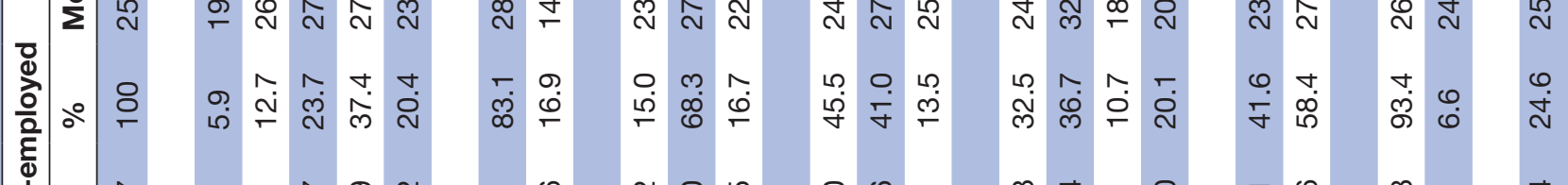

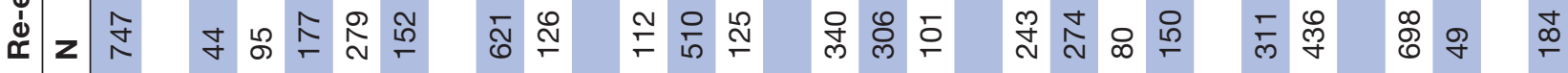

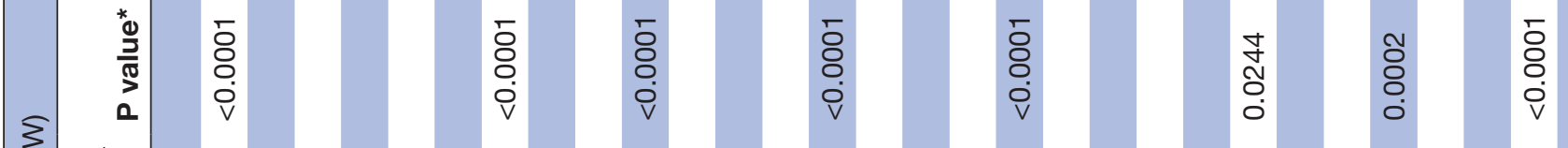

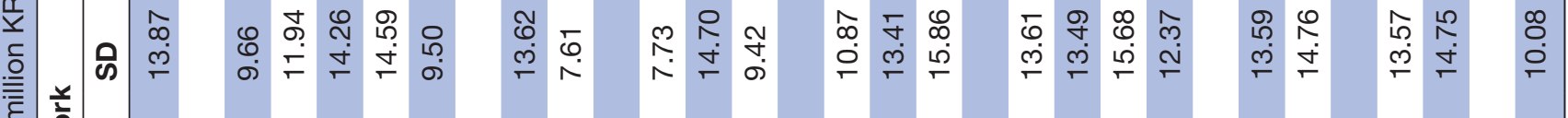

ฮั 㐘

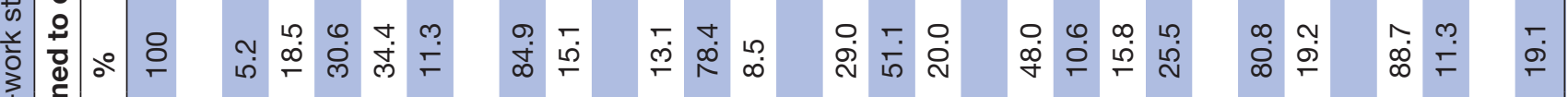

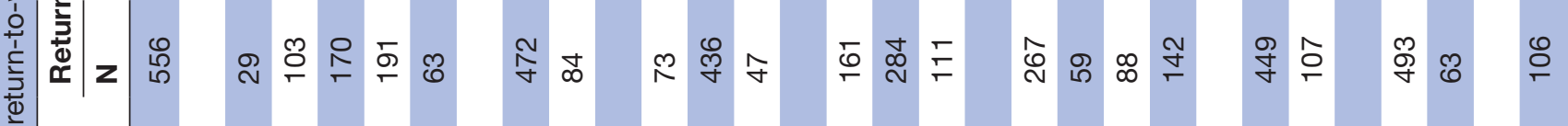

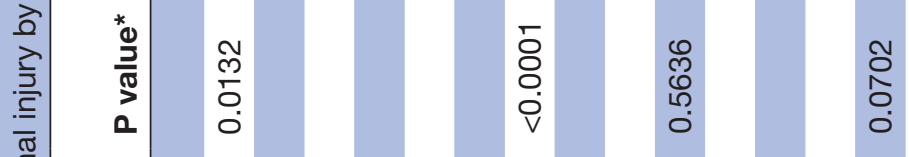

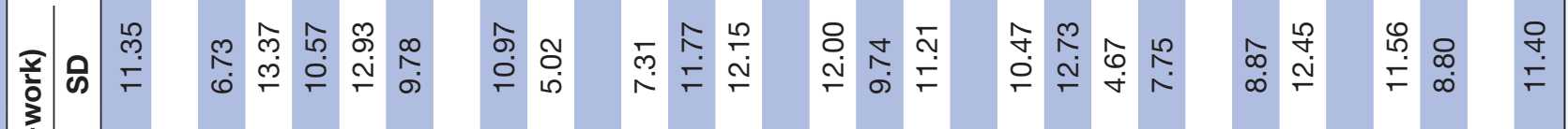

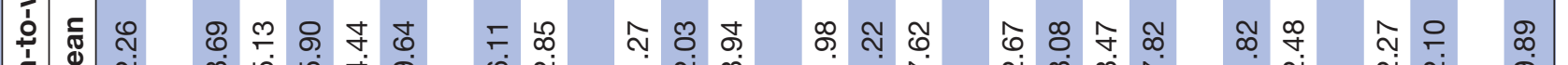
产

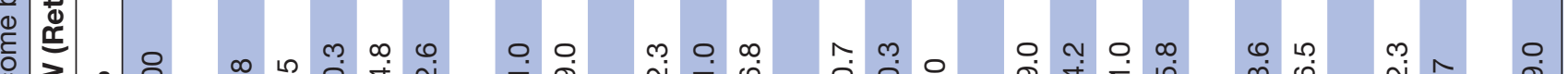

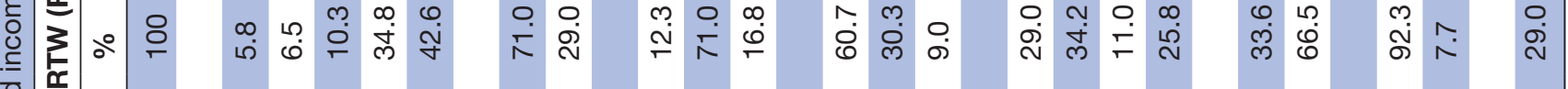
安 $\mathbf{z}$ 绍

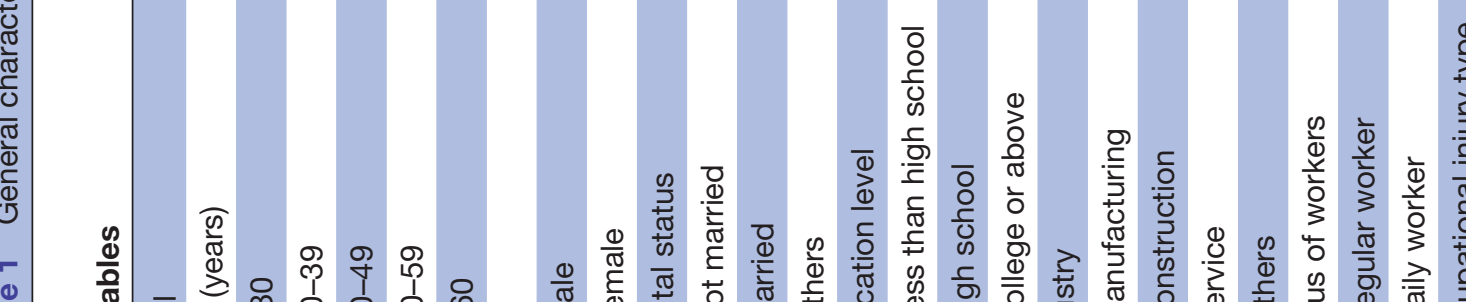

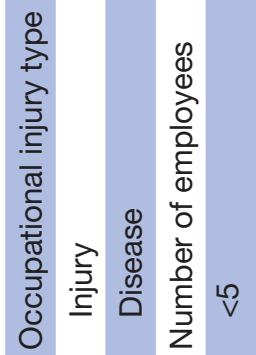

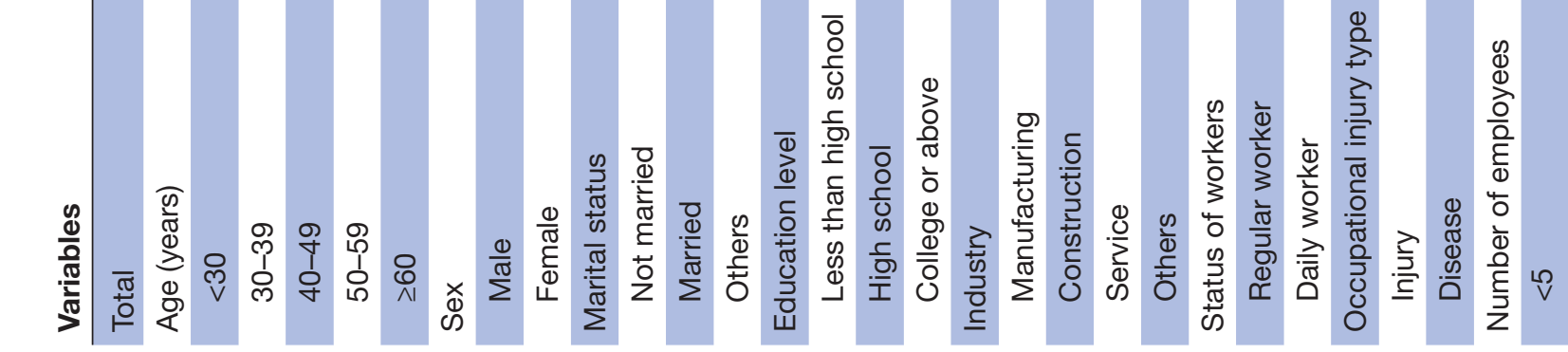




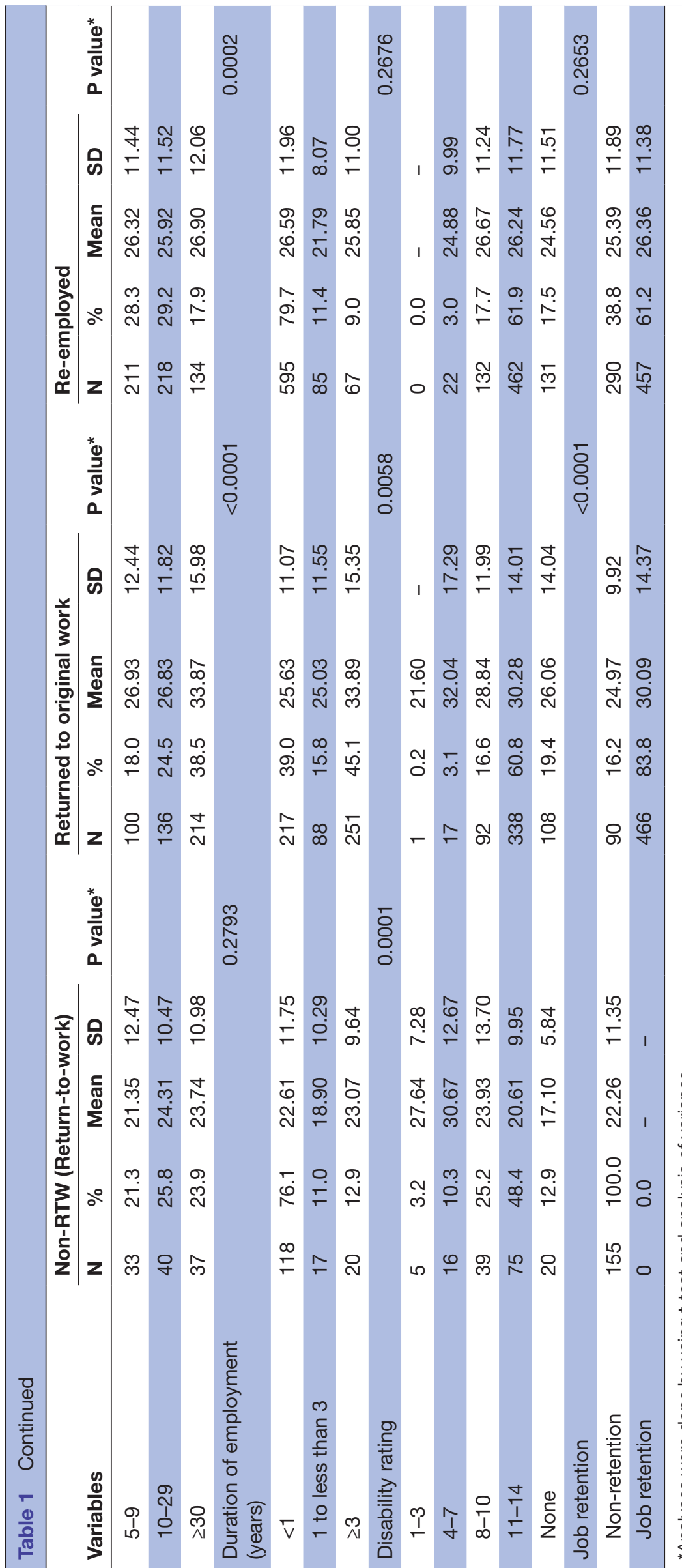


expected, the mean income of those who returned to their original workplace was highest, followed by those re-employed. The greatest proportion of individuals in the 'non-RTW' group belonged to those aged 60 years or older, whereas the greatest proportion of individuals in the 'returned to original work' group were aged between 40 and 49 years and the re-employed group were aged between 50 and 59 years. While $29 \%$ of the individuals in the 'non-RTW' group were females, only $15.1 \%$ of the individuals in the 'returned to original work' group and $16.9 \%$ of the individuals in the 're-employed' group were females. Regarding industry, the greatest proportion of individuals in the 'non-RTW' group and 're-employed' group belonged to the construction industry, whereas the greatest proportion of those in the 'returned to original work' group belonged to the manufacturing industry.

There were differences in annual incomes before and after occupational injury and the 5-year average income after the occupational injury by work status $(\mathrm{p}<0.0001$, $\mathrm{p}<0.0001$, respectively) (table 2 ). Income in the first year after injury was higher than income before the accident, regardless of work status. Although income rapidly lowers in the second year after injury, it gradually increases thereafter. Furthermore, only workers who were in the returned to original work group and the job retention group showed an increase in income after occupational injury as compared with before occupational injury. Workers who were in the non-return-to-work group and not in the job retention group experienced a sharp reduction in income after experiencing occupational injury.

There were no differences in annual incomes before and after occupational injury and the 5-year average income after occupational injury between the return to original work plus non-retention group and the re-employed plus job retention groups $(\mathrm{p}=0.5219, \mathrm{p}=0.3662$, respectively) (figure 1).

To compare workers' incomes before and after occupational injury in the injured workers, the value obtained by subtracting the before occupational injury income from the after occupational injury income was used as a dependent variable. Table 3 shows the change in income after occupational injury. After adjusting for all covariates, analyses revealed that the reduction in income was greater for men compared with women $(p=0.0088)$. In terms of industry, the reduction in income was significantly greater in construction workers compared with service workers $(\mathrm{p}<0.0001)$. The reduction in income for workers who were either re-employed or who did not return to work was significantly greater than for those who returned to original work $(\mathrm{p}<0.0001, \mathrm{p}<0.0001$, respectively). The reduction in income for workers in the non-retention group was significantly greater than the reduction in income for workers in the job retention group $(\mathrm{p}<0.0001)$.

This study used a GEE to investigate the effects of return to work and job retention status on income after an occupational injury. figure 2 provides the OR that income after an occupational injury would be higher than before, depending on workers' return to work and job retention status. In regard to workers' return to work, the OR that income after an occupational injury would be higher than that before an occupational injury was 3.17 (2.414.17) for those who returned to original work and 2.32 (1.81-2.97) for those re-employed compared with those who did not return to work. In terms of job retention, the OR that income after an occupational injury would be higher than that before an occupational injury was 1.27 (1.07-1.15) for those who retained their job as compared with those who did not. Such association did not differ by income distribution quartile (online supplemental table 1) and/or region (online supplemental table 2).

Figure 3 provides the OR that income after an occupational injury would be higher than that before an occupational injury depending on workers' work status. The OR for income being higher after occupational injury than before was 4.10 (3.16-5.32) for those who returned to original work and retained jobs compared with those who did not return to work and did not retain jobs. The ORs were 2.91 (2.26-3.75) for those who were re-employed and retained jobs and 2.96 (2.15-4.08) for those who returned to original work and did not retain jobs.

\section{DISCUSSION}

This study examined changes in income after an occupational injury according to return to work and job retention status in injured workers who completed medical care as well as to compare income before and after their occupational injury. These results are similar to previous findings. ${ }^{24}$

The income before occupational injury is more related to general income characteristics of workers than it is to injury-related characteristics. ${ }^{2}$ Income before occupational injury is higher for men, workers aged 40-49 years, workers with a higher education and workers employed by a company with a higher number of employees in the workplace (table 1). This is in line with the 2018 wage status report of the Ministry of Employment and Labor. ${ }^{13}$ The higher income for construction workers compared with those in the manufacturing or service sectors also align with previous results. ${ }^{4}$ As the methods of PSWCI rely on self-reported responses, results may not be accurate due to recall bias. ${ }^{36}$ Moreover, the proportion of daily workers is high in construction. ${ }^{38}{ }^{39}$ If workers who are paid daily responded by stating their wages including weekends, income may have been measured to be higher than the actual income. ${ }^{4}$

Regarding the differences in baseline characteristics that were apparent in table 1 , results were in alignment with some previous studies, but in conflict with others. In our study, we found that the greatest proportion of individuals in the 'non-RTW' group belonged to those aged 60 years or older, whereas the greatest proportion of individuals in the 'returned to original work' group were between 40 and 49 years and in the re-employed group were between 50 and 59 years. The implication that it is 


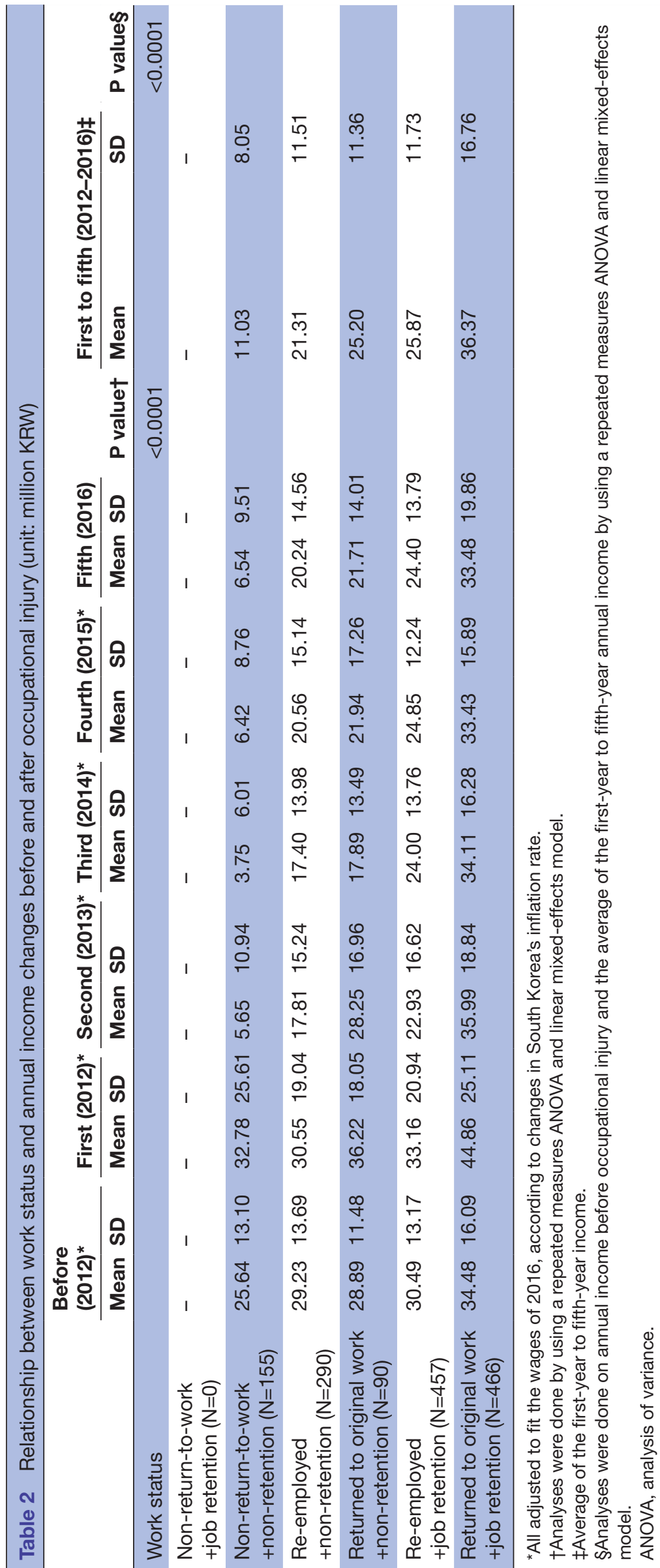




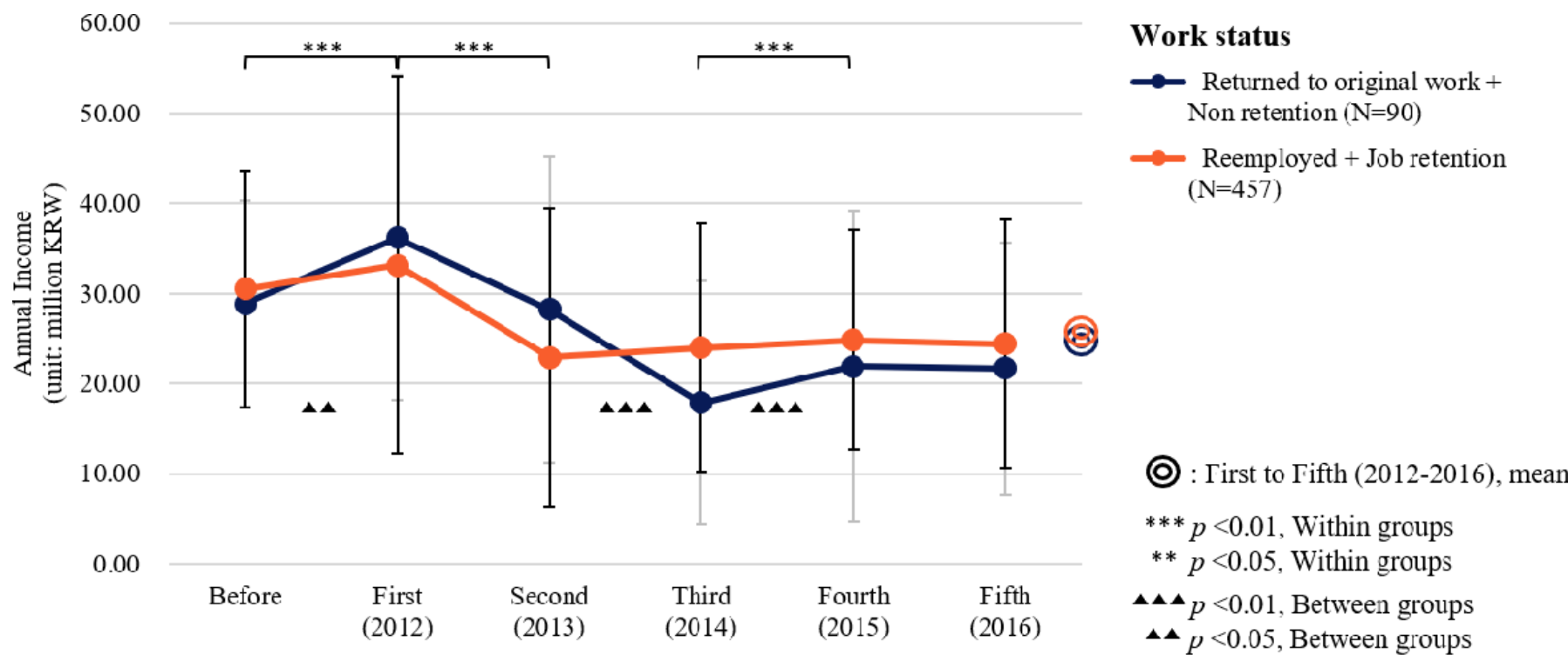

Year

Figure 1 Relationship between work status (returned to original work+non-retention, re-employed+job retention) and annual income before and after occupational injury (unit: million KRW).

more difficult for older adults to return to work is apparent in multiple studies; in a study of workers' compensation claims in Australia, older age was associated with greater days of wage replacement, even after adjusting for injury type and severity, ${ }^{40}$ while another study of $50-64$ years olds with permanent impairment from an occupational injury or illness found that older age (60-64 years of age compared with 55-59 or 50-54 years) was associated with early retirement, especially for manual jobs (compared with mixed or non-manual jobs) ${ }^{41}$ However, in one longitudinal study tracking 56 cases of work injury claims, there was no significant correlation between age and work status at 1,2 or 5 years post injury. ${ }^{42}$

In our study, gender also seemed to affect returning to work, with $29 \%$ of the individuals in 'non-RTW' group being females but only $15.1 \%$ of the individuals in the 'returned to original work' group and $16.9 \%$ of the individuals in the 're-employed' group being females. The association between gender and return to work following an injury are mixed; a previous study of individuals with a work-related mild traumatic brain injury found that women were more proactive than men in seeking and requesting medical and rehabilitation services, ${ }^{43}$ while another study found no significant association between gender and RTW in a sample of 872 individuals with work-related upper extremity injuries. ${ }^{44}$ Further studies of gender-related influences and RTW are recommended for an accurate understanding of this association.

Regarding industry, the greatest proportion of individuals in the 'non-RTW' group and 're-employed' group belonged to the construction industry, whereas the greatest proportion of those in the 'returned to original work' group belonged to the manufacturing industry.
Whether certain jobs result in greater proportions of RTW is a frequently researched topic; in a recent study of 8343 males and 5131 females with claims for occupational injuries, tradespersons and service workers had greater odds of returning to work following an injury than labourers or intermediate production/transport workers. ${ }^{45}$ In another study of 251 sick-listed employees from 40 different treatment and facilities in Norway, being in a low-strain job resulted in increased RTW, ${ }^{46}$ while in a study of 1341 patients with a traumatic brain injury, professionals and skilled workers were up to three times more likely than manual labourers to return to the workplace. ${ }^{47}$

Regarding the changes in income before and after occupational injury, the income in the first year after completion of medical care was higher than the income prior to occupational injury, regardless of return to work or job retention status. Income decreased markedly the following year and subsequently increased with each year (table 2). These results are similar to previous findings. The fact that income increases in the first year after the accident and decreases in the second year after the accident may be due to the disability compensation lump sum payment. Moreover, the reason income increases over time after the second year may be due to the return-towork status. ${ }^{24}$ In Korea, if an industrial accident is closed in accordance with the Industrial Accident Compensation Insurance Act, the workers' compensation insurance compensates the worker according to disability grades if the worker is deemed to have a disability at the time of such closure. Workers with disability ratings of 1-3 are provided with a pension payment. They can be paid half of the sum of the first to fourth year of payments in one lump sum if they wish. Workers with disability ratings of 
Table 3 Relationship between the general characteristics and post accident income minus the income before the occupational injury (unit: million KRW)

\begin{tabular}{clll}
\hline Variables & $\boldsymbol{B}^{*}$ & SE & P value \\
\hline Age (years) & & & \\
$<30$ & -0.60 & 1.23 & 0.6228 \\
$30-39$ & ref & & \\
$40-49$ & -3.05 & 0.75 & $<0.0001$ \\
$50-59$ & -4.85 & 0.83 & $<0.0001$ \\
$\geq 60$ & -5.47 & 0.93 & $<0.0001$ \\
Sex & & & \\
Male & -2.01 & 0.77 & 0.0088 \\
Female & ref & & \\
\hline
\end{tabular}

Marital status

\begin{tabular}{|llll|}
\hline Not married & -1.42 & 0.84 & 0.0907 \\
\hline Married & ref & & \\
\hline Others & -0.47 & 0.71 & 0.5141 \\
\hline Education level & & & \\
\hline Less than high school & -0.05 & 0.63 & 0.9413 \\
\hline High school & ref & & \\
\hline College or above & -0.12 & 0.79 & 0.8777 \\
\hline Industry & & & \\
\hline Manufacturing & -0.61 & 0.90 & 0.4944 \\
\hline Construction & -4.06 & 1.04 & $<0.0001$ \\
\hline Service & ref & & \\
\hline Others & -0.10 & 0.93 & 0.9119 \\
\hline Status of workers & & & \\
\hline Regular worker & ref & & \\
\hline Daily worker & -0.65 & 0.70 & 0.3497 \\
\hline Occupational injury type & & & \\
\hline Injury & -1.38 & 0.97 & 0.1538 \\
\hline Disease & ref & & \\
\hline Iumber of employ & & & \\
\hline
\end{tabular}

\section{Number of employees}

\begin{tabular}{llll}
$<5$ & ref & & \\
\hline $5-9$ & -2.48 & 0.76 & 0.0011 \\
\hline $10-29$ & -2.74 & 0.74 & 0.0002 \\
$\geq 30$ & -1.48 & 0.77 & 0.0550 \\
\hline $\begin{array}{l}\text { Duration of employment (years) } \\
<1\end{array}$ & & & \\
\hline 1 to less than 3 & -0.96 & 0.85 & 0.2541 \\
\hline 3 & ref & & \\
\hline Disability rating & -0.13 & 0.94 & 0.8883 \\
\hline $1-3$ & & & \\
\hline $4-7$ & ref & & \\
\hline $8-10$ & -2.66 & 4.26 & 0.5314 \\
\hline $11-14$ & -4.52 & 4.11 & 0.2720 \\
\hline None & -9.95 & 4.08 & 0.0149 \\
\hline & -11.57 & 4.12 & 0.0051 \\
\hline
\end{tabular}

Table 3 Continued

\begin{tabular}{llll}
\hline Variables & $\boldsymbol{B}^{*}$ & SE & P value \\
\hline Return to work & & & \\
Non-RTW & -10.24 & 1.09 & $<0.0001$ \\
Returned to original work & ref & & \\
$\begin{array}{l}\text { Re-employed } \\
\text { Job retention }\end{array}$ & -4.16 & 0.64 & $<0.0001$ \\
$\quad$ Non-retention & & & \\
Job retention & -3.45 & 0.62 & $<0.0001$ \\
\hline
\end{tabular}

*Statistical estimated from a linear mixed-effects model that adjusted for all other covariates excluding an interesting variant.

4-7 can select payment in pension or lump sum and can opt to receive half of the total sum for 2 years in one lump sum, should they choose to take the pension. Workers with disability ratings of 8-14 are paid in lump sums only. ${ }^{37}$

In figure 2, we compared the income levels of individuals who did not return to work post injury with those who did. Compared with workers who did not return to work, those who returned to their original workplace (3.17, 2.41-4.17) and those who were re-employed (2.32, 1.81-2.97) had higher incomes after occupational injury than before occupational injury. Workers who retained jobs for 24 months $(1.27,1.07-1.51)$ also had a higher income than those who did not (figure 2). It can therefore be said that returning to their original workplace and job retention are important factors for maintaining the income levels of workers involved in industrial accidents. ${ }^{4}$ However, it must be noted that overall, while there may be an initial increase in income from various compensation measures that are awarded by insurance companies and the government to individuals who have had an occupational injury, after a certain period (maximum of 5 years), all injured individuals in our investigation suffered from a decrease in income.

Returning to the original workplace is prioritised over re-employment for successful return to work $^{48}$; besides, there are no policies that protect re-employed workers involved in industrial accidents and that encourage employers to hire-and maintain employment forthose workers. ${ }^{5}$ The post injury income of the workers who were re-employed and who retained their jobs was at a level similar to that of the workers who returned to their original workplace but did not retain their jobs (figures 1 and 3). Rather than failing to retain jobs after returning to their original workplace, it may be more economically beneficial to be re-employed and to retain jobs. In addition, protection policies for re-employed workers or benefits for employers hiring re-employed workers should be considered. ${ }^{5}$

\section{Strengths and limitations}

This study has several strengths. First, the data used in the study are from the only panel study in Korea conducted by the KCOMWEL with a 5-year follow-up on the quality 


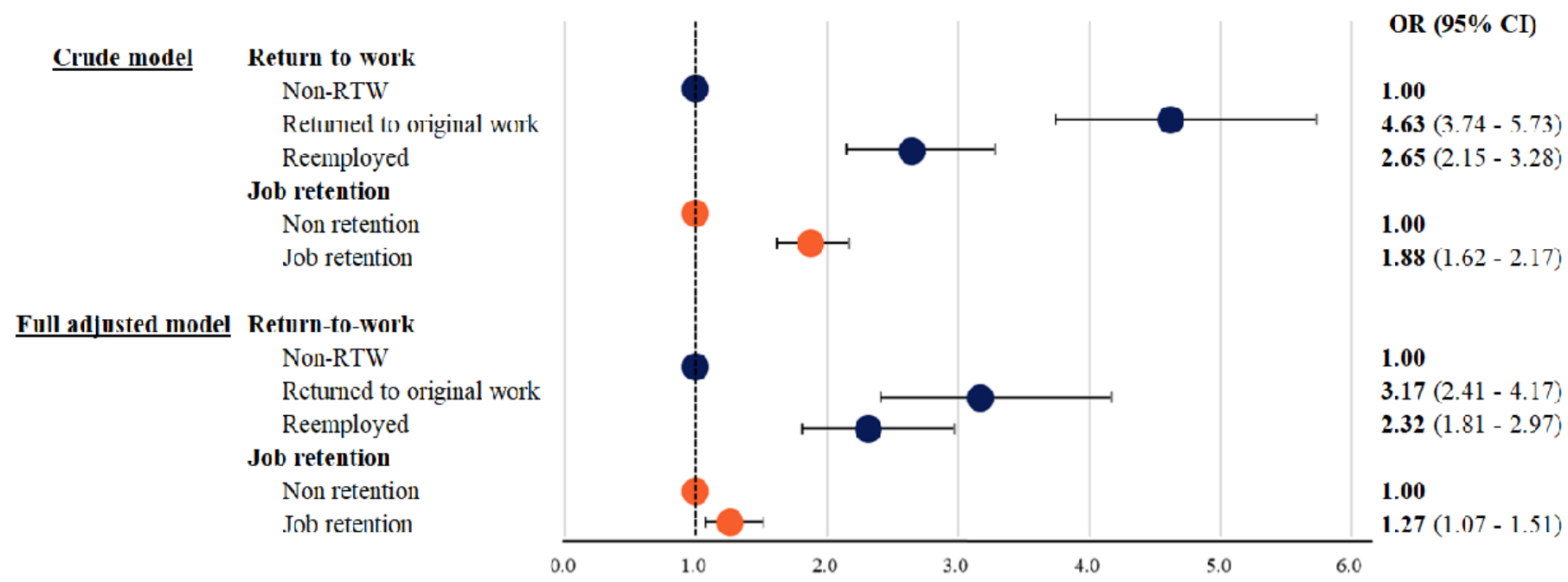

Figure 2 Generalised estimating equation with annual income after occupational injury by return to work and job retention.

of life of workers who had been involved in industrial accidents and who completed medical care in 2012. ${ }^{2434-36}$ The PSWCI is considered to be a nationally representative survey of workers in South Korea as they employ stratified systematic sampling methods according to sex, age, residential region, disability grade and the utilisation of a rehabilitation service that reflect the proportions of national statistics. ${ }^{45}$ Second, this study is the first to examine the changes in income based on return-to-work status and job retention for Korean workers involved in industrial accidents. Lastly, by using a longitudinal analysis strategy to analyse income value changes year by year, we were able to track the same workers from before and after their injury for a period of 5 years. By adjusting all values to fit the wages of 2016 according to changes in South Korea's inflation rate, we were able to provide income change values for our study population that reflected the general development in wages over the years. This resulted in a novel finding that income following an injury may increase slightly after an injury due to various compensation measures, but will eventually decrease to a level below the 'before injury' within 5 years' time, even with job retention.

One limitation to this study is that we did not consider the effect that a disability lump sum compensation would have on income after occupational injury. We therefore made an additional comparison using 5-year average incomes after occupational injury. ${ }^{2}$ Moreover, some answers-especially regarding income before occupational injury-can be affected by respondents' recall bias, as we analysed data obtained through interviews in a certain time frame. Furthermore, we were only able to adjust for the inflation rate in our analysis, but many longitudinal factors, including productivity growth, seasonal changes and economic events, that could not be controlled were likely to have affected the results of our analysis. Likewise, while various statistical techniques were employed to control for both item and unit non-responses, it was impossible to fully eliminate related biases. Although we employed a poststratification and non-response weight adjustment calculation to inflate base weights and minimise longitudinal bias, the multiple imputation of drop-outs may have been more appropriate in compensating for the loss of data. We also failed to impute the data for 13 individuals with missing information regarding income before and after an occupational accident, which may have skewed our results. Finally, because the year of the accident was not recorded, income before occupational injury was calculated using the duration of medical care. ${ }^{24}$

\section{Work status (N)}

Non return to work-Non retention (155)

Nom relum to work-Job relention (0)

Returned to original work+Non retention (90)

Returned to original work । Job retention (466)

Recmployed+Non retention (290)

Reemployed+Job retention (457)

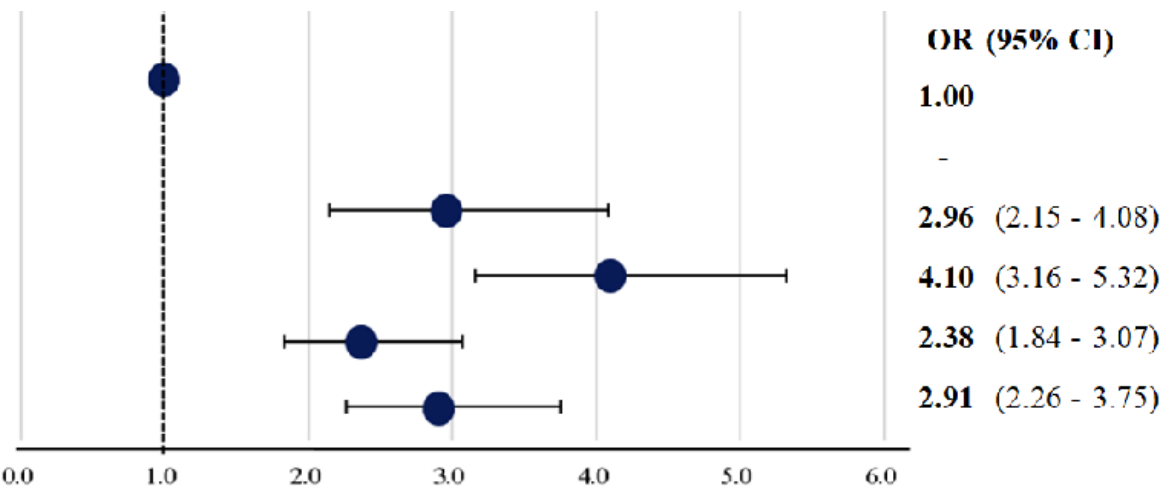

Figure 3 Generalised estimating equation with annual income after occupational injury by return to work and job retention. 


\section{CONCLUSIONS}

In conclusion, the income of workers involved in occupational injuries generally decreased, compared with their income before the occupational injury. Although workers who returned to their original workplace and retained their jobs had increased incomes after occupational injury, other workers had decreased incomes. However, workers who returned to their original workplace but did not retain jobs had similar incomes to workers who were re-employed and retained their jobs. This signifies that although returning to the original workplace is very important to maintain the economic level of workers involved in occupational injuries, it is also important to retain jobs, even if the individual cannot return to their original workplace. Based on these findings, there is an urgent need for policies that can help workers involved in occupational injuries to maintain their jobs.

\section{Author affiliations}

${ }^{1}$ Graduate School of Public Health, Yonsei University, Seoul, South Korea

${ }^{2}$ The Institute for Occupational Health, Yonsei University College of Medicine, Seoul, South Korea

${ }^{3}$ Department of Occupational and Environmental Medicine, Ajou University School of Medicine, Suwon, South Korea

${ }^{4}$ Department of Preventive Medicine and Public Health, Yonsei University College of Medicine, Seoul, South Korea

${ }^{5}$ Labor Welfare Research Institute, Korea Workers' Compensation \& Welfare Service, Seoul, South Korea

${ }^{6}$ Department of Hospital Administration, Graduate School of Public Health, Yonsei University, Seoul, South Korea

${ }^{7}$ Institute of Health Services Research, Yonsei University, Seoul, South Korea

Acknowledgements The authors would like to thank the Labor Welfare Research Center of Korea Workers' Compensation and Welfare Service for making this study possible by providing the data from the Panel Study of Worker's Compensation Insurance.

Contributors SWB conceived and planned the study, performed the analysis, wrote the original draft with input from all authors, visualised the results, validated the study and contributed to the interpretation of the results. IJ conceived and planned the study, performed the analysis, wrote the original draft with input from all authors and contributed to the interpretation of the results. J-HY conceived and planned the study, performed the analysis and validated the study. SWL conceived and planned the study and visualised the results. THK conceived and planned the study, performed the analysis and validated the study. J-UW conceived and planned the study, validated the study, contributed to the interpretation of the results and supervised the entire process. All authors read and approved the final manuscript.

Funding The authors have not declared a specific grant for this research from any funding agency in the public, commercial or not-for-profit sectors.

Competing interests None declared.

Patient consent for publication Not required.

Ethics approval The Institutional Review Board of Yonsei University Health System approved this study (Y-2019-0101).

Provenance and peer review Not commissioned; externally peer reviewed.

Data availability statement № data are available. Not applicable.

Supplemental material This content has been supplied by the author(s). It has not been vetted by BMJ Publishing Group Limited (BMJ) and may not have been peer-reviewed. Any opinions or recommendations discussed are solely those of the author(s) and are not endorsed by BMJ. BMJ disclaims all liability and responsibility arising from any reliance placed on the content. Where the content includes any translated material, BMJ does not warrant the accuracy and reliability of the translations (including but not limited to local regulations, clinical guidelines, terminology, drug names and drug dosages), and is not responsible for any error and/or omissions arising from translation and adaptation or otherwise.
Open access This is an open access article distributed in accordance with the Creative Commons Attribution Non Commercial (CC BY-NC 4.0) license, which permits others to distribute, remix, adapt, build upon this work non-commercially, and license their derivative works on different terms, provided the original work is properly cited, appropriate credit is given, any changes made indicated, and the use is non-commercial. See: http://creativecommons.org/licenses/by-nc/4.0/.

\section{ORCID iDs}

Suk Won Bae http://orcid.org/0000-0002-2250-9604

Inchul Jeong http://orcid.org/0000-0002-8619-5034

Jin-Ha Yoon http://orcid.org/0000-0003-4198-2955

\section{REFERENCES}

1 Ministry of Employment and Labor. Analysis of occupational accidents. Sejong, Korea: Ministry of Employment and Labor, 2019. http://www.moel.go.kr/policy/policydata/view.do?bbs_seq= 20190300037

2 Bae S, Yun S, Lee Y, et al. Income changes due to disability ratings and participation in economic activities caused by industrial accidents: a population-based study of data from the fourth panel study of workers' compensation insurance (PSWCl). Int J Environ Res Public Health 2018;15:2478.

3 Ministry of Employment and Labor. Industrial accidents occurrence status. Sejong, Korea: Ministry of Employment and Labor, 2019. http://www.moel.go.kr/policy/policydata/view.do?bbs_seq= 20190500060

4 Bae SW, Oh SS, Park WM, et al. Changes in income after an industrial accident according to industry and return-to-work status. Int J Environ Res Public Health 2019;16:2603.

5 Jeong I, Park JB, Kim HR, et al. Impacts of return-to-work type and period on job retention in workers with occupational injuries and diseases. J Korean Med Sci 2017;33:e2.

6 Haupt TC, Pillay K. Investigating the true costs of construction accidents. Journal of Engineering, Design and Technology 2016;14:373-419.

7 Lee H-K, Suh K-H. A qualitative study on the psychological problems of injured workers. Korean J Health Psychol 2014;19:431-42.

8 Park SK. Factors associated with depression among injured workers with disabilities returning to work in South Korea: comparison of return to pre-injury job with work at a new firm. Kor J Soc Welf Res 2013:37:149-74.

9 Lee S-J. The return-to-work system of the industrially injured workers in Korea. J Vocat Rehabil 2011;20:1-34.

$10 \mathrm{Kim}$ JW. An analysis of the effect of rehabilitation policy for the industrial accident disabled on employment performance. Korean $J$ Public Admin 2013;51:247-76.

11 Woo M. The Importance of the Introduction of the Industrial Accident Insurance Program in the Development of Korean Welfare Policy - The Formation of Welfare Policy and the Developmental State Intervention. Korean Journal of Sociology 2007;41:154-85.

$12 \mathrm{Kim}$ I, Rhie J, Yoon J-D, et al. Current situation and issue of industrial accident compensation insurance. J Korean Med Sci 2012;27 Suppl:S47-54.

13 Ministry of Employment and Labor. Edition of the employment and labor white paper. Sejong, Korea: Ministry of Employment and Labor, 2019. http://www.moel.go.kr/info/publicdata/majorpublish/ majorPublishView.do?bbs_seq=20190800069

14 Zhu Y, Chen PY, Zhao W. Injured workers in China: injustice, conflict and social unrest. International Labour Review 2014;153:635-47.

15 Takala J, Hämäläinen P, Saarela KL, et al. Global estimates of the burden of injury and illness at work in 2012. J Occup Environ Hyg 2014;11:326-37.

16 Bültmann U, Franche R-L, Hogg-Johnson S, et al. Health status, work limitations, and return-to-work trajectories in injured workers with musculoskeletal disorders. Qual Life Res 2007;16:1167-78.

17 Sullivan M, Adams H, Thibault P, et al. Return to work helps maintain treatment gains in the rehabilitation of whiplash injury. Pain 2017:158:980-7.

18 Kang HT, Im HJ, Kim YK, et al. Predictors of return to work and job retention after work-related injury or illness. Korean Journal of Occupational and Environmental Medicine 2006;18:221-31.

19 Krause N, Frank JW, Dasinger LK, et al. Determinants of duration of disability and return-to-work after work-related injury and illness: challenges for future research. Am J Ind Med 2001;40:464-84.

20 Turner JA, Franklin G, Turk DC. Predictors of chronic disability in injured workers: a systematic literature synthesis. Am J Ind Med 2000;38:707-22. 
21 Jeong WM, Park CY, Koo JW, et al. Predictors of return to work in occupational injured workers. Korean Journal of Occupational and Environmental Medicine 2003;15:119-31.

22 Corbière M, Renard M, St-Arnaud L, et al. Union perceptions of factors related to the return to work of employees with depression. $J$ Occup Rehabil 2015;25:335-47.

23 Shi Q, Sinden K, MacDermid JC, et al. A systematic review of prognostic factors for return to work following work-related traumatic hand injury. J Hand Ther 2014;27:55-62.

24 Lee JH. Evaluation of the affective factors for return-to-work of injured worker. Seoul: Graduate School of Health Science and Management, Yonsei University, 2009.

25 Won J-U, Seok H, Rhie J, et al. Hospital qualities related to return to work from occupational injury after controlling for injury severity as well as occupational characteristics. J Korean Med Sci 2016;31:695-701.

26 Lee W, Yoon J-H, Roh J, et al. Factors related to the physician and the employer influencing successful return to work in Korea: results from the first panel study of workers' compensation insurance (PSWCI). Ann Occup Environ Med 2015;27:27.

27 Rhie J, Jeong I, Won JU. Return-To-Work according to impairment type among occupationally injured workers in Korea. $J$ Korean Med Sci 2013;28:1581-6.

28 Park S-K, Ahn C-M. Predictors of job retention among worker's compensation clients in South Korea. Soc Welf Policy 2006;26:177-94.

29 Park SK. Successful return to work and related factors among job injured workers in Korea. J Rehabil Res 2012;16:293-318.

30 Hamer H, Gandhi R, Wong S, et al. Predicting return to work following treatment of chronic pain disorder. Occup Med 2013;63:253-9.

31 Mroz TM, Carlini AR, Archer KR, et al. Frequency and cost of claims by injury type from a state workers' compensation fund from 1998 through 2008. Arch Phys Med Rehabil 2014;95:1048-54.

32 Rudbeck M, Johansen JP, Omland Øyvind. A follow-up study on return to work in the year after reporting an occupational injury stratified by outcome of the workers' compensation system. J Occup Environ Med 2018;60:542-7.

33 Dong XS, Wang X, Largay JA, et al. Economic consequences of workplace injuries in the United States: findings from the National longitudinal survey of youth (NLSY79). Am J Ind Med 2016;59:106-18.

34 Seok H, Yoon J-H, Roh J, et al. The association between subjective socioeconomic status and health inequity in victims of occupational accidents in Korea. J Occup Health 2017;59:38-45.
35 Choi W-S, Kim B-K, Kim K-D, et al. Impact of the number of painful stimuli on life satisfaction among Korean industrial accident workers completing convalescence: dual mediating effects of self-esteem and sleeping time. Ind Health 2016;54:460-8.

36 Seok $\mathrm{H}$, Yoon J-H, Lee W, et al. The perceived socioeconomic status is an important factor of health recovery for victims of occupational accidents in Korea. J Korean Med Sci 2016;31:164-70.

37 Industrial Accident Compensation Insurance Act. Korea Ministry of government legislation. Seoul, Korea: Industrial Accident Compensation Insurance Act, Korea, 2019. http://www.lawnb.com/ Info/ContentView?sid=L000001760

38 Tadesse S, Israel D. Occupational injuries among building construction workers in Addis Ababa, Ethiopia. J Occup Med Toxicol 2016;11:16.

39 Amuedo-Dorantes C. Work transitions into and out of involuntary temporary employment in a segmented market: evidence from Spain. ILR Review 2000;53:309-25.

40 Fan JK, Black O, Smith PM. Examining age differences in duration of wage replacement by injury characteristics. Occup Med 2016;66:698-705.

41 Scott KA, Liao Q, Fisher GG, et al. Early labor force exit subsequent to permanently impairing occupational injury or illness among workers 50-64 years of age. Am J Ind Med 2018;61:317-25.

42 Craig M, Hill W, Englehart K, et al. Return to work after occupational injury and upper limb amputation. Occup Med 2017;67:227-9.

43 Stergiou-Kita M, Mansfield E, Sokoloff S, et al. Gender influences on return to work after mild traumatic brain injury. Arch Phys Med Rehabil 2016;97:S40-5.

44 von Schroeder HP, Xue CR, Yak A, et al. Factors associated with unsuccessful return-to-work following work-related upper extremity injury. Occup Med 2020;70:434-8.

45 Akbarzadeh Khorshidi H, Marembo M, Aickelin U. Predictors of return to work for occupational rehabilitation users in work-related injury insurance claims: insights from mental health. J Occup Rehabil 2019;29:740-53.

46 Aamland A, Maeland S, SJSjophc M. Sick-listed workers' expectations about and experiences with independent medical evaluation: a qualitative interview study from Norway. Scand J Prim Health Care 2018;36:134-41.

47 Walker WC, Marwitz JH, Kreutzer JS, et al. Occupational categories and return to work after traumatic brain injury: a multicenter study. Arch Phys Med Rehabil 2006;87:1576-82.

48 Young AE. Employment maintenance and the factors that impact it after vocational rehabilitation and return to work. Disabil Rehabil 2010;32:1621-32. 